\title{
Facilities Audit in Training Health Care Built Environment
}

\author{
Ahmad Ezanee Hashim ${ }^{1}$, Siti Aida Samikon ${ }^{2, *}$, Mohamad Sufian Hasim ${ }^{1}$ \\ ${ }^{1}$ Faculty of Architecture, Planning, and Surveying, Universiti Teknologi MARA (UiTM), Malaysia \\ ${ }^{2}$ Faculty of Science, Technology, Engineering and Mathematics, International University of Malaya-Wales (IUMW), Malaysia
}

Copyright $\bigcirc 2018$ by authors, all rights reserved. Authors agree that this article remains permanently open access under the terms of the Creative Commons Attribution License 4.0 International License

\begin{abstract}
Healthcare organisations have recognised the powerful impact of supply breakdowns and have exploited supply chain management for their quality program, especially regarding lean operations. There are many contributors to poor working environments in the healthcare sector. Some studies relate to inadequate equipment, such as patient lifts and facilities for safe disposal of syringes, needles, and medical waste. However, one area that has so far largely been overlooked relates to the built environment. This study aims to investigate strategic Facilities Management (FM) as a function to support the objectives of providing efficient services to healthcare sector through measuring user satisfaction focusing on public training hospital building. This research involved correlation analysis. The findings show that there is a strong significant relationship among the building performance criteria and the importance of post occupancy evaluation (POE) guidelines in functional and technical performance criteria. Based on the findings, this study proposed the establishment of facilities management and the implementation of systematic annual operation program to ensure that management and services are useful. Secondly, it is intended to establish certain policy instruments such as information tools and economic instruments for hospital management to meet the needs of patients in future hospital development.
\end{abstract}

Keywords Sustainable, Facilities Management Audit, Public Healthcare

\section{Introduction}

Healthcare organisations have recognised the powerful impact of supply breakdowns and have exploited supply chain management for their quality program, especially regarding lean operations. There are many contributors to poor working environments in the healthcare sector. Some studies relate to inadequate equipment, such as patient lifts and facilities for safe disposal of syringes, needles, and medical waste. However, one area that has so far largely been overlooked relates to the built environment. This study aims to investigate strategic Facilities Management (FM) as a function to support the objectives of providing efficient services to healthcare sector through measuring user satisfaction. According to Edogho et al. [1], though the FM unit put in lot of efforts in the development, operation and maintenance of appropriate support facilities for the performance of the core functions of teaching and research, such efforts does not show positive reflections during periodic assessment of the level of customer satisfaction. This, in part, can be corrected through the use of the soft skills of effective communication, development of functional periodic reports, providing continuous stream of information through asset analysis and functional budget.

Facility management covers a vast scope of real estate management, financial management, change management, human resources management, health and safety, contract management, building and engineering services maintenance, and domestic services [2]. EN 15221-1:2006 defines Facilities Management as the integration of processes within an organization to maintain and develop the agreed services which support and improve the effectiveness of its primary activities [3]. Effective facility management is vital to the success of an organisation by contributing to the achievement of its strategic and operational objectives [4]. Shohet et al. [5] recognised that a successful FM is "highly dependent on cost effectiveness and performance management." Facility management professionals work in a complex environment in which they have to keep up with a significant amount of information provided by various domains. Facilities management is a balance between technical, managerial and business acumen that may be related to operational, tactical and strategic decision-making processes [6] and the management of multi-disciplinary activities to ensure continuous functionality of the built environment by linking an 
integrating people, place, processes and technology [7].

One of the complex types of facilities in which facility managers was faced with massive amounts of information on a daily or even hourly basis and require critical decisions is healthcare facility management. Healthcare facilities include hospitals, clinics, dental offices, out-patient surgery centres, birthing centres, and nursing homes [8]. Hospitals are 24-hour working facilities that employ a wide variety of trades, from medical staff to mechanical maintenance, medical equipment maintenance, housekeeping, food service, building and grounds maintenance, laundry, and administrative staff [8].

In $10^{\text {th }}$ Malaysian Plan for the years $2011-2015$, the plan to work together towards improving health care system is based on the concept of "1 Care for 1Malaysia", with its relation to National Mission Thrust "To Improve the Standard and Sustainability of Quality of Life". "1 Care" is a restructured national health system that is responsive and provides a choice of quality health care, ensuring universal coverage for health care needs of population based on solidarity and equity. Despite that, as the population increases, the number of admissions and number of outpatient visits will increase. This means there is more demand for healthcare services. It is estimated that annually there is a $3 \%$ increase in admissions to Ministry of Health (MOH) hospitals. This shows it is necessary to stress the need for studies into hospital-related operative efficiency for the purpose of comparatively assessing both systems and establishing efficient performance patterns [9]. In this respect, this study is to review and analyze the general performance satisfaction level of a public teaching hospital.

\section{Managing Healing Facilities in Healthcare Built Environment}

A health service system of a nation cannot be seen in isolation from the broader socio-political and economic forces prevailing in a country. The nature of its development reflects the broader ideological changes that take place in a society over a period of time [10]. Healthcare delivery processes are becoming increasingly technological in nature and hence technology mastery is becoming more critical [11]. Hospitals are among the most complex building which comprises a wide range of services and functional units. According to Miller et al [12], new concept of hospital and healthcare has emerged and started the transition from the traditional "provider-centered" to a "consumer-centered" healthcare system. Through observation, a government hospital in Malaysia still in the traditional "provider-centred" healthcare system compared to developed countries. Thus, only through a study of healthcare employee commitment revealed key predictors are organisational support, job skill enrichment, quality control, and a culture of continuous learning [13]. Hospitals need to reliant on gained information regarding user's satisfactions to assist in the diagnosis, management, and education for better and improved services and practice thus can allow the building management and health ministry to identify the weakness of healthcare services provided and improve it.

Through proper training and development, healthcare services will strengthen professionals to function more effectively. Studies show that setting a high-level goal for employees will lead healthcare to be more effective, patient-centered, and efficient [14]. It is important to determine the criteria on which health care service quality should be assessed. Such criteria can be technical or functional [15] or technical and process-related [16]. The first phase of health service development in the country was marked by an extension of the health service infrastructure and development of primary healthcare centres across the country $[17,18]$.

A training hospital is a hospital that provides clinical education and training to future and current doctors, nurses, and other health professionals, in addition to delivering medical care to patients. They are affiliated with medical schools or universities (hence the alternative term is university hospital), and may be owned by a university or may form part of a wider regional or national health system. Despite the growth in undergraduate medical education over the last decade, causing the expansion of a new kind of hospital used for teaching where large state or public district hospitals affiliated with both public and private medical schools for teaching purposes in addition to service provision and research for the affiliated university staffs. However, in this case, previously service oriented hospitals are made to function as a teaching hospital, allowing public hospitals to be used for teaching undergraduate medicine. Some teaching hospitals also have a commitment to research and are centres for experimental, innovative and technically sophisticated services. For these multitudes of functions, a teaching hospital must be owned by a medical school or a university but regarding clinical service provision, it may be part of a national health system [19].

In Malaysia, there are only three teaching hospitals under a medical faculty or university. The fourth is scheduled to start operation in late 2016. There are University Malaya Medical Centre (UMMC), University Kebangsaan Malaysia Medical Centre (UKM), and Hospital University Sains Malaysia (USM). These teaching hospitals are under the purview of the Ministry of Higher Education. According to Fauzi [19], Malaysia needs more hospitals, and the way forward is to build more teaching hospitals. International Islamic University Malaysia (IIUM) teaching hospital project is a step in the right direction which that will lead to an improvement in the healthcare delivery in the country. Therefore, this research is to analyse the level of satisfaction and perception of training students and hospital staffs in 
functional and technical performance aspect through POE in teaching hospital buildings and to improve the public teaching hospital buildings environment and enhance the user's satisfaction through POE.

Figure 1 and figure 2 shows general teaching hospital relationships and its primary clinical relationships by Carr [20]. The diagrams show the movement and communication of people, materials, and waste. The physical configuration of a hospital, its transportation, and logistics systems are inextricably intertwined. In a large hospital complex, a typical nursing unit is a principal element of the overall configuration. Nursing units today tend to be more compact shapes compared to the past in an attempt to shorten the distance between the nurse station and the patient's bed.

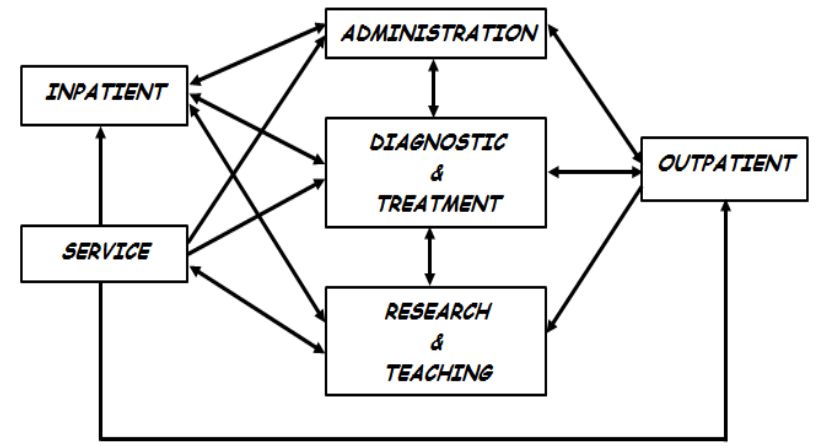

Figure 1. General Hospital Relationship [20],

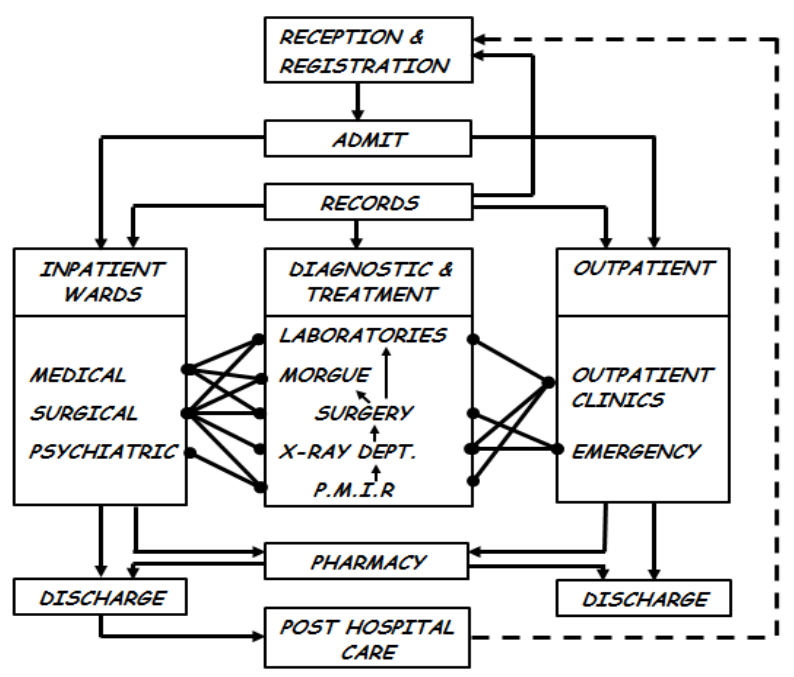

Figure 2. Major Clinical Relationship [20]

Binggeli [21] defined building performance as to ensure that buildings perform precisely to the diverse range of user needs and requirements. The main building performance elements are energy efficiency, indoor air quality, air moisture and thermal comfort. Atkin, B et al [2] states that building performance could be done through two types of services which are in-house for the core business and outsourcing for the non-core. The building users are the people who understand how a building should perform. It does not only depend on its provided facilities but also on the design envelope and reliability of the building life [22].

A building should provide the basic elements that give comfort which allow the occupant to do activities satisfactorily who they have a set of predetermined expectations of services quality and a perception of what to be delivered. When expectations exceed the perceived service, a service quality gap appears and dissatisfaction will be the outcome. Satisfaction is the state felt by a person who has experienced a performance outcome which fulfilled expectations. Satisfaction is thus a function of relative levels of expectation and perceived performance [23].

\subsection{Occupant's Satisfaction}

Customers are anyone who expects to receive the maximum benefit of a service and complying their satisfaction in the health sector is a very complex process. They are in more than one tier, and there are medical and administration staffs, patients and visitors, government as a funding party, and society in general. Each of these requiring the facility's support in different degrees based on their different values, beliefs, perceptions and expectations [24]. However, understanding of customer perceptions is essential to remain competitive in today's market. The organisation must not only know the level of customer satisfaction with its current product or service but also know the degree of customer satisfaction with its competitors' [25]. FM process design faces its first major challenge when it comes to the term "customer". EN 15221-1: 2006 differentiates between "client", "customer" and "end user". "Client" is defined as the organisation that specifies needs and procures facility services by means of an FM agreement. "Customer" is defined as an organisational unit that specifies and orders the delivery of facility services within the condition of an FM agreement, and the "end user" is defined as the person receiving facility services in a permanent or temporary way [3]. To ensure satisfaction of various customer needs, it is essential that facilities management identifies focuses and monitors key performance indicators and it is highly subjective. Therefore, it is important for the organisation to interact with its customers if it wishes to improve its services [26] and improve the image of the organisation [27]. They need to constitute the rational framework for the distribution of human and other resources between and within health care facilities [28]. The variables that affect patients and non-patients /customers satisfaction were categorised into three main groups; (i) room features (ii) services by the facilities management and (iii) the environment. According to Kursunluoglu [29], another stronger tool of customer satisfaction is service quality. Lepkova et al. [30], supported these by designed the dependence between the quality of service, customer 
satisfaction, and profitability is interrelated as shown in Figure 3.

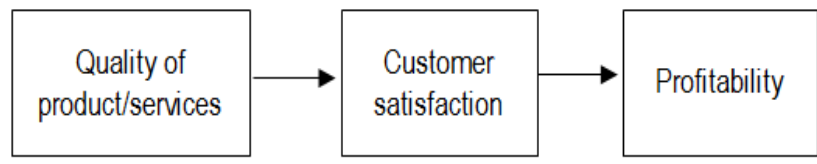

Sources: Quoted by Lepkova et al. [30] from (Fečikova, 2004)

Figure 3. Dependence between Quality, Satisfaction, and Profitability

\subsection{Post Occupancy Evaluation (POE)}

Post occupancy evaluation (POE) is seen as one of building appraisal which provides an opportunity for an organisation to see how well a particular facility meets their requirements from various viewpoints with its purpose to improve the current situation and to aid in the design of perspective conducive buildings. In cyclical building process, evaluation is the missing link in the design process. Evaluation of briefing program and design are three linked activities drawing information from the systematic look at how people use existing environments. Analysing environments leads to programming [26]. POE is the process of systematically evaluating the extent to which a facility, once occupied for a period of time, meets the intended organisational goals and user-occupant needs [31]. S. Turpin-Brooks et al. [32] quoting Zimring et al. [33] define POE as "examinations of the effectiveness for human users of occupied design environments." Briefly, it is an evaluation of the performance of buildings after being used and occupied and makes it clear that the information gain from POE is important to make improvement for a better-built environment. An informal definition of POE by Blyth et al. [34], which emphasises the building's lifecycle, states: "POE is a way of providing feedback throughout a building's lifecycle from initial concept through to occupation. The information from feedback can be used for informing future projects, whether it is in the process of delivery or technical performance of the building".

POE is generally defined as a systematic evaluation process in which occupied buildings meets all occupant's requirements in term of design, occupancy and comfort. POE in the indoor environment factors approaches the best evaluation in internal occupant efficiency and activities. Nicol et al. [35] states that with systematic POE assessment and application not only reduce the financial cost but it also improve the life quality, productivity and building comfort. Effective learning and teaching in hospital buildings should be carried out in the conducive comfortable indoor environment as to make sure the students give full concentration and focus in teaching lesson [36]. (American Association for the Advancement of Science, 1990). UNESCO [37], highlighted that the education management should give a social care in implementing a plan for rehabilitation, reconstruction and replacement of damaged school building.

POE can be used to adaptive reuse, by using the provided data in solving the problem and issues contributed to teaching hospital buildings. Information gained will help in repeating mistakes in which the available data will inform specific future decisions and support improvement of conducive building delivery process. It creates a quality mechanism and monitoring process if a building does not meet a given standard [38]. POE emphasis on the needs of building occupant [39]. POE refers to evaluating the extent to which a building, once occupied for a period of time, meets the user-occupier needs [40]. The building is review during six to twelve months after building completion and occupied. However, the evaluation could be done in any time frame to improve building performance and function. .Nevertheless, such as education building or teaching hospital buildings, it should have a specific modular schedule of evaluation as it might disturb the learning and teaching process.

The building's function is to provide shelter and space for activities that carried out by the building occupants. The facilities in the building must perform and appropriate to its use. The needs of occupants are affected by the building performance and occupant's evaluation of the buildings. Post Occupancy Evaluation (POE) is a method to empower the occupant's opinion as for the benchmark of building performance evaluation. POE comprises as one of the techniques that are used to evaluate whether a building meets the user's requirement [41]. Wauters [42] confirms the value of "user satisfaction surveys" as a herald to service-level benchmarking and successive recommendations for improving facilities services. Used as a feed forward process, POE can support evidence-based design throughout the planning and implementation of new and existing facilities [43]. Thus, the objective of this research is to analyse the level of satisfaction of user's need in functional and technical performance aspect of POE. Secondly, to propose a guideline on building performance framework based on user' satisfaction evaluation done for public teaching hospitals building. Hafizi et. al [44], based on Lewis [27], suggested facilities management is responsible for safety and wellness of building operation and maintenance of facilities at the managed building. Poor work quality and insufficient work programme for maintaining and managing the facilities may lead to the accident, injury, and death [44]. Previous study on health care building assessment through post-occupancy audit, Hashim et.al [45] highlighted that comprehensive documentation in the context of knowledge during planning and implementation, design expectations and how decisions are being made can be used by the design consultant and hospital managers as a reference data to improve the specific services area for future design. Considering the definitions brought by various scholars, it can be put into generalization that Post Occupancy Evaluation is the formal evaluation of a building that focuses on user satisfaction, measured with social science-based tools of interviews, surveys, focus 
groups, systematic observation, and behavioral mapping for achieving continuous performance improvement throughout the building's lifecycle [46].

\subsection{Technical and Functional Elements in Building Performance}

There is several widely accepted performance criteria considered in. To exploring the performance of the built environment requires an understanding of how various elements in its design provide for the needs of occupants. In POE processes there are two elements of building performance criteria will be discussed which are;

\section{i. Technical elements}

Technical Elements are physical characteristics of the built environment that contribute to the performance of basic building systems such as mechanical, electrical and fire safety systems, as well as other building elements related to acoustics, lighting and durability [47]. It focuses mainly on the daily and scheduled maintenance services provided to the end users of the office buildings. In other words, technical elements can be characterised as the background environment for carrying out activities [48].

\section{ii. Functional elements}

This aspect covers the management service delivery attributes or the service profiles that the management holds [47]. The functional elements of a building support the activities within it, and they must be responsive to the specific needs of the organisation and occupants, both quantitatively and qualitatively [48]. They are those design factors that deal with the fit of the built environment with the activities it was designed to support.

\subsection{Performance Criteria Considered in POE}

There is several widely accepted performance criteria considered in, some were conveyed by Preiser et al., [40]. The performance criteria were divided into three levels of priority; Health, Safety, and Security performance; Functionality, Efficiency, and Workflow; Psychological, Social, Cultural, and Aesthetic performance. To conduct a POE, the establishment of performance criteria is important, lists of performance criteria in order of priority are health, safety, security, function, efficiency, workflow, psychological, social and cultural performance [49] (Preiser and Schramm, 2002). Table 1 shown the performance criteria for POE [50] are more of functional and technical performance to address how well the building organisational goals, how well the user's needs are accommodated, and how well the physical system in building performs [51].

A study on a student housing facility in Saudi Arabia [48] has examined which user satisfaction survey was developed to obtain the students' qualitative feedback on their experience with the designed indoor environment. The study found that the student residents were satisfied with the five main performance categories identified. Hassanain [48] used of five technical performance requirements, including thermal comfort; acoustic comfort; visual comfort; indoor air quality; and fire safety. Five functional requirements include interior and exterior finish systems; room layout and furniture quality; support services; the efficiency of circulation; and proximity to other facilities on campus. Izran [51] come out with a 15 performance criteria and 39 parameters framework that need to be considered in POE of building performance.

Table 1. The areas covered in a functional and technical performance evaluation

\begin{tabular}{|l|l|}
\hline Performance Criteria & \multicolumn{2}{|c|}{ Description } \\
\hline Functional & Achievement of original business objectives \\
\hline Strategic Value & Harmonious, neutral, iconic, powerful, bland \\
\hline Aesthetics and Image & Size, relationships, adaptability \\
\hline Space & $\begin{array}{l}\text { Environmental aspects: lighting, temperature, ventilation, } \\
\text { noise, user control }\end{array}$ \\
\hline Comfort & $\begin{array}{l}\text { Services and equipment: completeness, capacity, } \\
\text { positioning }\end{array}$ \\
\hline Amenity & Cleaning, routine maintenance, security, essential changes \\
\hline Serviceability & Energy cost, water and waste, leaser, cleaning, insurances \\
\hline Operational Cost & $\begin{array}{l}\text { Initial construction cost, cost of operating, maintenance and } \\
\text { repairs, replacement costs, alteration, demolition }\end{array}$ \\
\hline Life style cost & $\begin{array}{l}\text { Booking and space allocation systems, user support } \\
\text { systems, help desks, manuals, training }\end{array}$ \\
\hline $\begin{array}{l}\text { Operational } \\
\text { Management }\end{array}$ & Lighting, heating, ventilation, acoustics \\
\hline Technical & Energy consumption, water consumption, CO2 output \\
\hline Physical systems & Ability to accommodate changes \\
\hline $\begin{array}{l}\text { Environmental } \\
\text { systems }\end{array}$ & $\begin{array}{l}\text { Robustness need for routine maintenance, incidence of } \\
\text { down time" for unplanned technical reasons }\end{array}$ \\
\hline Adaptability &
\end{tabular}




\section{Methodology}

The methodology consisted of a questionnaire survey, semi-structured interview, and a case study on selected public hospitals in Selangor, Malaysia. The case study samples were located in a highly dense urban area in Selangor, Malaysia. The research questions were tested through a semi-structured interview with the expert officer related to managing the operational in government's training hospital building, and preliminary questionnaire survey to training students, clinical and administrative staffs in Selangor district. Through literature reviews, variables have been identified, and key variables have been selected for the closed- ended questionnaire and interview. An extensive literature review questionnaire survey was prepared based on the primary objective to review and analyse the performance level of the training hospital, the standard of satisfaction of users' needs on technical and functional building performance, and implementation of the strategy for the betterment of practice in training hospital building. The case studies selected were teaching hospital in Selangor districts. Questionnaires distributed to three locations which are University Kebangsaan Malaysia Medical Centre (UKMMC), University Malaya Medical Centre (UMMC) and Hospital Sungai Buloh. The respondents' samples are limited to administrative staffs, training students, and clinical staffs as shown in table 2 below.

The questionnaires data were analysed using frequency analysis through Likert scale approach and descriptive analysis through mean score analysis. The data from questionnaires are processed by using Statistical Package for Social Science (SPSS) computer software to ease frequency analysis purposes.

\section{Data Collection}

The data collection process involved primary and secondary data. The primary data was collected by questionnaires which aim at health sector by identifying the management and critical success factor of facilities manager in a public hospital in Selangor. The selection of public hospital is based on numbers of bed and in operation for ten years and above. The hospitals are Pusat Perubatan Universiti Malaya (PPUM), Pusat Perubatan Universiti Malaya (PPUKM), and Hospital Sungai Buloh (HSP). In-depth assessment and face to face interview with hospital management and consultant of services provider were conducted. Inputs from hospital management were required to evaluate their management practice, issues and problems faced and to obtain the critical success factor of facilities manager required. The semi-structured interviews were conducted with the aids of survey questionnaire form, supported by visual photographs and illustration after each interview. On-site assessment or site visits are a necessary and essential part for verifying the information obtains a review to the actual condition of a teaching hospital. All of the data collected was schedule and analyses.

The analysis begins by reviewing the public hospital case study, informing the reader of the location, no of beds and facilities provided. The data collected was analysed using statistical technique comprised of frequencies and percentages as well as graphical methods.

\section{Result Analysis and Findings}

Discussion on the results will cover the summary of correlation analysis between building performance criteria and the importance of POE guideline. It is divided into two categories which for technical and functional performance criteria. The finding outcome is used to allocate and identify the proposed framework guidelines for the public teaching hospital building.

\subsection{Technical Performance Criteria}

Table 1 shows the correlation analysis between Building Performance Criteria and Importance of POE Guideline. The majority of the correlation coefficient for building performance criteria in areas of technical performance have high correlation and low correlation with the correlation score for the importance of POE guideline. Thus, this finding can be used and considered in selecting as criteria allocated in proposed guidelines which are relevant in evaluating the performance of public teaching hospital buildings in Malaysia. Figure 4 shows findings that depicted from the Table 3 .

The correlation coefficient between technical building performance and the importance of POE Guideline are positively high based on security, safety, and efficiency and health criteria. The high correlation coefficients indicate that level of importance of technical building performance criteria based on the POE has a strong positive relationship with the need of POE framework guideline in a public teaching hospital. 
Table 2. Summary of total respondents

\begin{tabular}{|c|c|c|c|c|}
\hline \multirow{2}{*}{ Feedbacks } & \multicolumn{3}{|c|}{ HOSPITALS } & \multirow{2}{*}{ TOTAL } \\
\cline { 2 - 5 } & UMMC & SG BULOH & $21 / 25$ & $72 / 75$ \\
\hline Administrative & $22 / 25$ & $25 / 25$ & $25 / 25$ & $75 / 75$ \\
\hline Clinical Staff & $25 / 25$ & $25 / 25$ & $25 / 25$ & $75 / 75$ \\
\hline Training Students & $25 / 25$ & $25 / 25$ & DKMMC \\
\hline \multicolumn{2}{r}{} \\
\hline
\end{tabular}

Table 3. Correlation Analysis between Building Performance Criteria and Importance of POE Guideline (Technical Performance Criteria)

\begin{tabular}{|c|c|c|c|c|c|}
\hline \multirow{3}{*}{ No } & \multicolumn{3}{|c|}{ Correlation Coefficient } & \multirow{3}{*}{ Average } & \multirow{3}{*}{ Region } \\
\hline & \multicolumn{3}{|c|}{$\begin{array}{l}\text { "Excellent" if } 0.80<\text { Correlation Coefficients } \leq 1.00 \\
\text { "Very Good" if } 0.65<\text { Correlation Coefficients }<0.80 \\
\text { "Good" if } 0.50<\text { Correlation Coefficients }<0.65 \\
\text { "Poor" if } 0.00 \leq \text { Correlation Coefficients }<0.50\end{array}$} & & \\
\hline & UMMC & Hospital Sg.Buloh & UKMMC & & \\
\hline Health & 0.375 & 0.837 & 0.693 & 0.64 & High Correlation \\
\hline Safety & 0.518 & 0.861 & 0.790 & 0.72 & High Correlation \\
\hline Security & 0.432 & 0.861 & 0.899 & 0.73 & High Correlation \\
\hline Efficiency & 0.435 & 0.744 & 0.851 & 0.68 & High Correlation \\
\hline Durability & 0.282 & 0.595 & 0.570 & 0.48 & Low Correlation \\
\hline Adaptability & 0.277 & 0.585 & 0.561 & 0.47 & Low Correlation \\
\hline
\end{tabular}

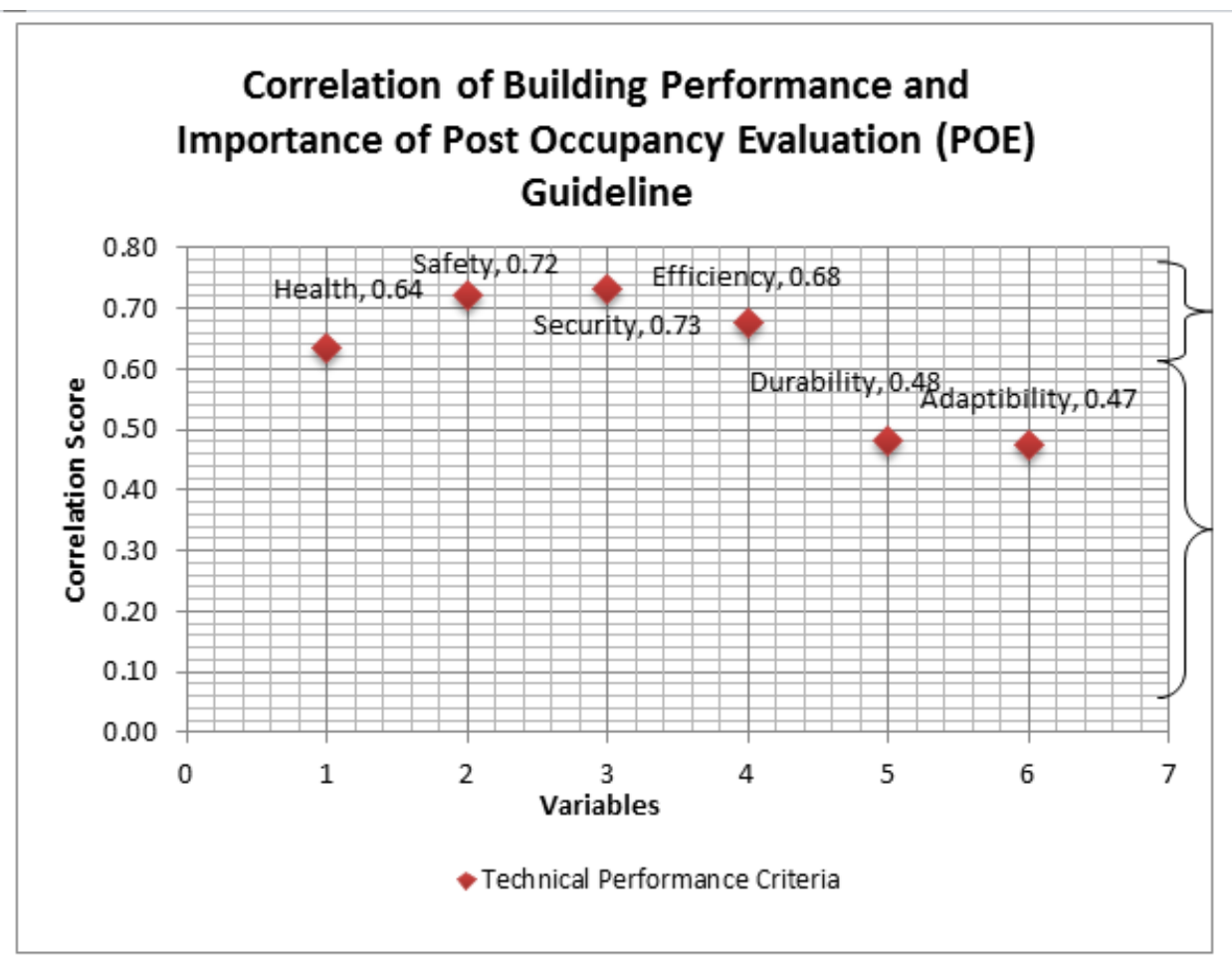

Region A: High Correlation

Region B: Low Correlation

Figure 4. Correlation Analysis between Building Performance Criteria and Importance of POE Guideline (Technical Performance Criteria) 
The correlation coefficient between technical building performance and the importance of POE Guideline are low based on durability and adaptability criteria. The low correlation coefficients show that level of importance of technical building performance criteria based on the POE has a low relationship with the need of POE framework guideline in a public teaching hospital. Despite having low correlation, it does not constitute negative correlation. This indicates the low correlation is the difference in perception between the building occupants' perception which is influenced by their background, working experience, knowledge, and technical skills.

\subsection{Functional Performance Criteria}

Table 4 below illustrates the correlation between functional building performance criteria and the importance of POE guideline. The correlation coefficient between functional building performance and the importance of POE Guideline are positively high based on serviceability and comfort criteria. The high correlation coefficients indicate that level of importance of functional building performance criteria based on the POE has a strong positive relationship with the need of POE framework guideline in a public teaching hospital.

The correlation coefficient between functional building performance and the importance of POE Guideline are low based on aesthetics, social, culture, functionality, operative and maintenance (O\&M) circulation and psychology criteria. The low correlation coefficients show that level of importance of technical building performance criteria based on the POE has a low relationship with the need of POE framework guideline in a public teaching hospital. Despite having low correlation, it does not constitute negative correlation. This indicates the low correlation is the difference in perception between the building occupants due to different perception and expectation on criteria stipulated in questionnaires which are influenced by their background, working experience, knowledge, and technical skills.

These findings from the level of building performance and the importance of POE guideline determines the proposed guidelines which are needed to evaluate the performance of public teaching hospital in Malaysia in respective to functional and technical performance. The proposed guideline is shown in Figure 6.

Table 4. Correlation Analysis between Building Performance Criteria and Importance of POE Guideline (Functional Performance Criteria)

\begin{tabular}{|c|c|c|c|c|c|}
\hline \multirow[t]{3}{*}{ No } & \multicolumn{3}{|c|}{ Correlation Coefficient } & \multirow[t]{3}{*}{ Average } & \multirow[t]{3}{*}{ Region } \\
\hline & \multicolumn{3}{|c|}{$\begin{array}{l}\text { "Excellent" if } 0.80<\text { Correlation Coefficients } \leq 1.00 \\
\text { "Very Good" if } 0.65<\text { Correlation Coefficients }<0.80 \\
\text { "Good" if } 0.50<\text { Correlation Coefficients }<0.65 \\
\text { "Poor" if } 0.00 \leq \text { Correlation Coefficients }<0.50\end{array}$} & & \\
\hline & UMMC & Hospital $\mathrm{Sg}$.Buloh & UKMMC & & \\
\hline Functionality & 0.146 & 0.617 & 0.445 & 0.40 & Low Correlation \\
\hline Social & 0.166 & 0.347 & 0.203 & 0.24 & Low Correlation \\
\hline Psychology & 0.365 & 0.492 & 0.581 & 0.48 & Low Correlation \\
\hline Aesthetics & 0.163 & 0.160 & 0.158 & 0.16 & Low Correlation \\
\hline O\&M & 0.415 & 0.351 & 0.540 & 0.44 & Low Correlation \\
\hline Comfort & 0.553 & 0.434 & 0.694 & 0.56 & High Correlation \\
\hline Circulation & 0.284 & 0.413 & 0.591 & 0.43 & Low Correlation \\
\hline Culture & 0.179 & 0.403 & 0.491 & 0.36 & Low Correlation \\
\hline Serviceability & 0.425 & 0.552 & 0.678 & 0.55 & High Correlation \\
\hline
\end{tabular}




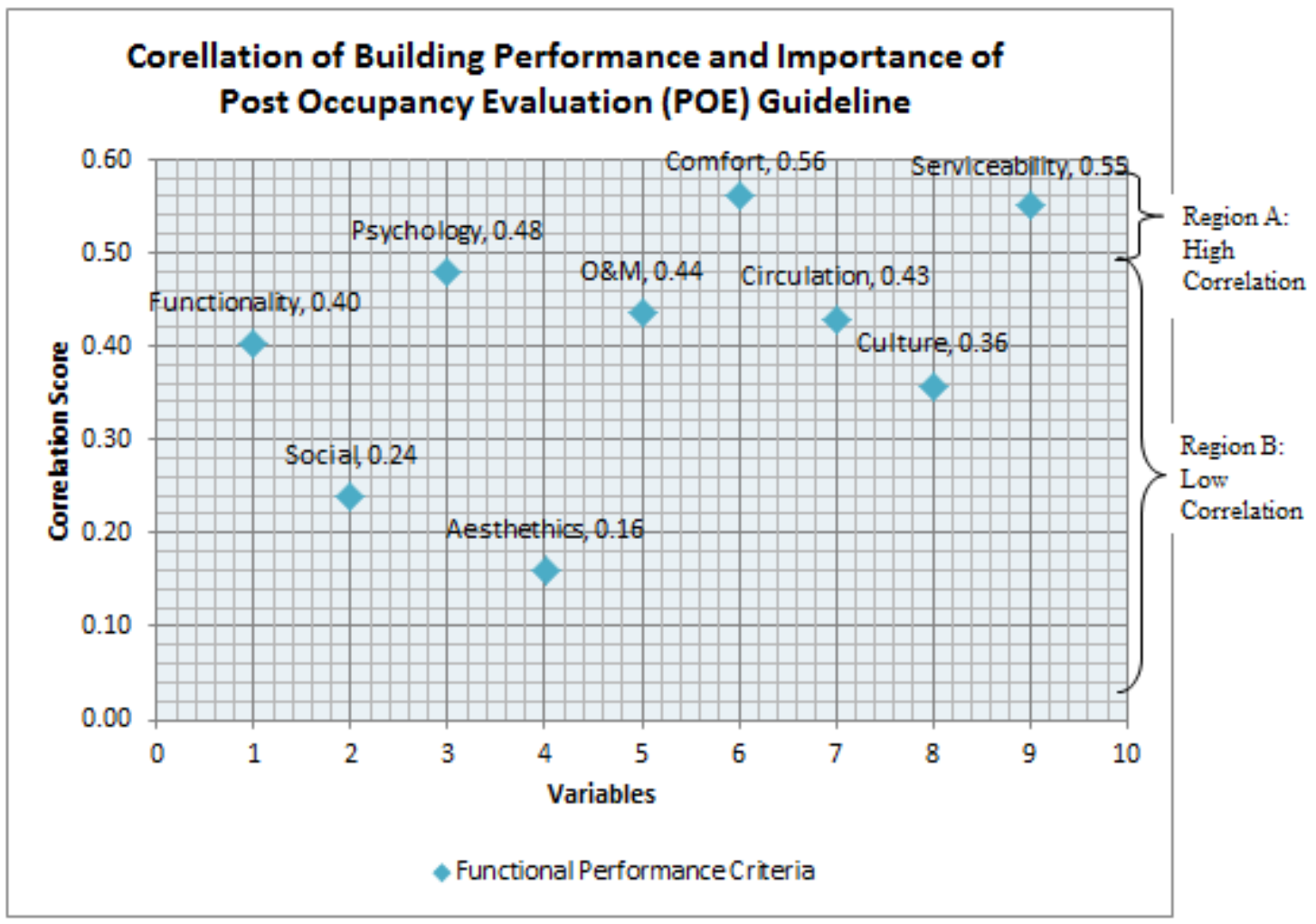

Figure 5. Correlation Analysis between Building Performance Criteria and Importance of POE Guideline (Functional Performance Criteria)

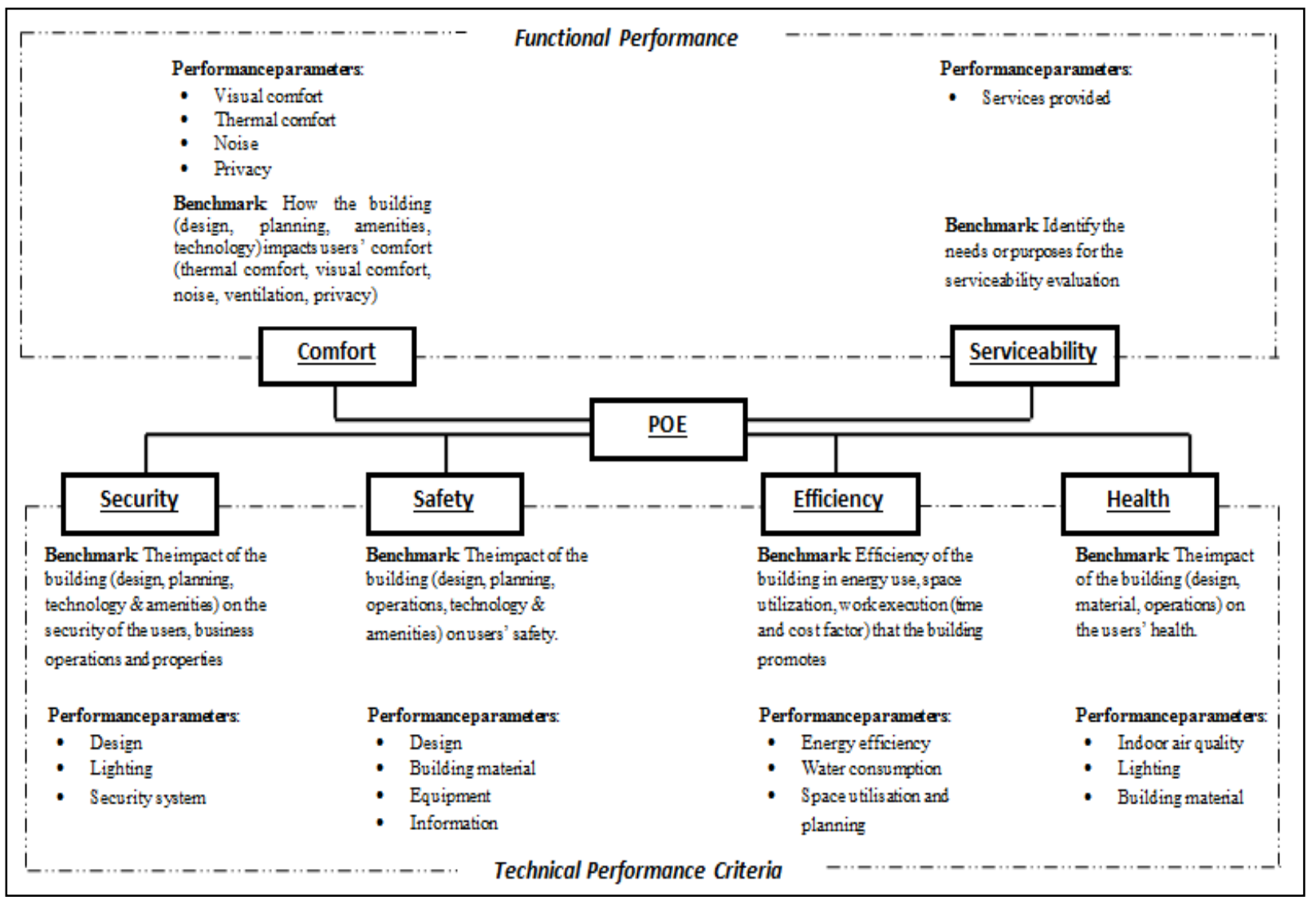

Figure 6. Proposed Framework of guideline on building performance in areas of functional and technical performance 


\section{Finding and Conclusions}

This research involved correlation analysis of the results obtained. The findings show that there is a strong significant relationship among the building performance criteria and the importance of POE guidelines in functional and technical performance criteria. POE guidelines enable to address the problem and issues and enhance the satisfaction level of the public teaching health care and hospital organisation. The results gained from the study firstly can assist in portraying the general review of current state of facilities performance level on public health care teaching hospital building. Secondly, it enabled to comprehend the future betterment in fulfilling the user's demand and satisfaction. Identifying user's satisfaction will enable the facilities management and relevant ministries in identifying the weaknesses and improve the provided healthcare services. The results gained can assist in providing relevant databases in achieving an appropriate level of building performance criteria in the public teaching hospital building. Thus, the study fulfilled the research hypotheses; (i) conducive working environment would demonstrate more productive working performance and increase productivity; (ii) functional and technical performance factors of POE determine the user satisfaction in highly dynamic hospital building environment; and (iii) the established POE guidelines will address the problem and issues and enhance the satisfaction level of public teaching hospital organization

Higher user satisfaction and better service utilisation in health care public teaching hospital building there is a need for more comprehensive documentation in the of the context of knowledge at preliminary planning and implementation, design expectations and how design decisions are made. The lack of detailed information will limit the designer evaluation's ability to understand the user's requirements, expectation, and satisfaction entirely.

\section{REFERENCES}

[1] Edoghogho Ogbeifun, Charles Mbohwa, Jan-Harm C. Pretorius, (2016) "Facilities management unit: improving self-image before its customers", Facilities, Vol. 34 Issue: 13/14,pp. 956-975, doi: 10.1108/ F-05-2015-0035

[2] Atkin, B. and Brooks, A. (2009), Total Facilities Management, Wiley-Blackwell, Oxford.

[3] European Committee for Standardisation (2006), Facility Management - Part 1: Terms and Definitions, EN 15221-1: 2006, European Committee for Standardisation, Brussels.

[4] Chanter, B. and Swallow, P. (2007), Building Maintenance Management, Blackwell Publishing, Oxford

[5] Shohet, I.M., and Lavy, S. (2004), "Healthcare facilities management: state of the art review", Facilities, Vol. 22, pp. 210-220.

[6] Kamaruzzaman, S. N., \& Ahmad Zawawi, E. M. (2010). Development of facilities management in Malaysia. Journal of Facilities Management, 8, 75-81.

[7] Mohd Noor, M. N., \& Pitt, M. (2010). Defining facilities management (FM) in the Malaysian Perspectives. ERES Conference. Milano. Retrieved from http://www.propertyfinance.it/sitoeres/contents/papers/id2. pdf

[8] OSHA (2012), "Healthcare facilities", United States Department of Labors, Occupational Safety and Health Administration (OSHA), available at www.osha.gov/SLTC/healthcarefacilities/ (accessed 1 February 2012).

[9] Boerma, T. and C. Abou-Zahr (2010). "Monitoring and Evaluation of Health Systems Strengthening and Operational Framework." World Health Organization, Geneva.

[10] Chhavi Sodhi, Pushpendra Singh, (2016) "Health service system in transition: An assessment of the influence of the British and US healthcare systems on the evolution of health services in India", International Journal of Health Governance, Vol. 21 Issue: 4,pp. 204-221, doi: 10.1108/ IJHG-03-2016-0020

[11] Wright, P.M., Gardner, T.M., Monynihan, L.M. and Allen, M.R. (2005), "The relationship between HR practices and firm performance: examining causal order", Personnel Psychology, Vol. 58 No. 2, pp. 409-66.

[12] Miller, R. L. and E. S. Swensson (2002). "Hospital and Healthcare Facility Design." ( $2^{\text {nd }}$ Ed.). New York: London

[13] Kontoghiorghes and C. Bryant, N., (2004). "Exploring employee commitment in a services organisation in healthcare insurance industry."

[14] Greenhalgh, T., Humphrey, C., Hughes, J., Macfarlane, F., Butler, C. and Pawson, R.A.Y. (2009), "How do you modernise a health service? A realist evaluation of wholescale transformation in London", Milbank Quarterly, Vol. 87 No. 2, pp. 391-416.

[15] Babakus and E. Mangold, W. G. (1992). "Adapting the SERVQUAL scale to hospital services: An empirical investigation. Health Services Research." 26(6): 767-786.

[16] Zeithaml, Valarie A. and Mary Jo Bitner (2000), Services Marketing, New York: McGraw- Hill Research and Information, Vol. 29 No. 6, pp. 469-72.

[17] Duggal, R. (2005), "Historical review of health policy making”, in Gangolli, L.V., Duggal, R. and Shukla, A. (Eds), Review of Healthcare in India, Centre for Enquiry into Health and Allied Themes, Mumbai, pp. 21-41.

[18] Reddy, K.S., Patel, V., Jha, P., Paul, V.K., Shiva Kumar, A.K. and Dandona, L. (2011), "India: towards universal health coverage 7 - towards achievement of universal health care in India by 2020: a call to action", The Lancet, Vol. 377 No. 9767, pp. 760-768.

[19] Fauzi, M. (2012). "Malaysia needs more teaching hospitals." The International Medical Journal Malaysia Vol.11 No.(2). 
[20] Carr, R. F. (2011). Hospital. Retrieved May 7, 2012, from http://www.wbdg.org/design/hospital.php\#mjr

[21] Binggeli, C. (2003). "Building Systems for Interior Designers".

[22] Jan Hensen. (2010). Simulation For Performance Based Building and Systems Design" pp 1-14

[23] Horn, W. (2002). "Applying customer satisfaction theory to community college planning of student services."

[24] Payne, T. (2000) Facilities Management: A Strategy for Success, Oxford, UK, Chandos Publishing (Oxford) Limited.

[25] Gonza'Lez, M. E., Quesada, G., Mack, R. \& Urrutia, I. (2005) Building an Activity-Based Costing Hospital Model Using Quality Function Deployment and Benchmarking. Benchmarking: An International Journal, 12 310-329.

[26] Barrett, P. \& Baldry, D. (2003) Facilities Management: Towards Best Practice, UK, Blackwell Publishing.

[27] Lewis, B. T. (2000) Facility Manager's Portable Handbook New York, USA, McGraw-Hill.

[28] Kontodimopoulos, N., Nanos, P., \& Niakas D. (2006). Balancing efficiency of health services and equity of access in remote areas in Greece. Health Policy, 76, 49-57.

[29] Kursunluoglu, E. (2011). Customer service effects on customer satisfaction and customer loyalty: A field research in shopping centres in Izmir City- Turkey. International Journal of Business and Social Sciences, 2, 52-59.

[30] Lepkova, N., \& Žūkaitè-Jefimovienè, G. (2012). Study on customer satisfaction with facilities management services in Lithuania. Slovak Journal of Civil Engineering, 1-16.

[31] Preiser, W.F.E., Rabinowitz, H.Z. and White, E.T. (1988). Post Occupancy Evaluation. New York: Van Nostrand Reinhold.

[32] S. Turpin-Brooks, G. Viccars, (2006),"The development of robust methods of post-occupancy evaluation", Facilities, Vol. 24 Iss: 5 pp. $177-196$

[33] Zimring, C., Rashid, M. and Kampschroer, K. (2005), Facility Performance Evaluation (FPE), Whole Building Design Guide, available at: www.wbdg.org/design/fpe.php

[34] Blyth, A., Gilby, A. and Barlex, M. (2006), Guide to Post-Occupancy Evaluation, AUDE, Cambridge, available at:

www.aude.ac.uk/filegrab/1GuidetoPostOccupancyEvaluati on. pdf?ref1/414 (accessed March 2010).

[35] Nicol, F. and Roaf, S. (2005). Post Occupancy Evaluation and Field Studies of Thermal Comfort. Building Research and Information. 33(4), pp 338-346

[36] American Association for the Advancement of Science. (1990). "Effective Teaching and Learning " Retrieved October 20, 2012, from

http://www.project2061.org/publications/sfaa/online/chap1 3.htm
[37] United Nations Educational, Scientific and Cultural Organization (UNESCO). (2006). "Learning Spaces and School Facilities" Retrieved October 18, 2011, from http://unesdoc.unesco.org/images/0014/001478/147878e.pd

[38] Lackney JA, Zaifen P. Post-occupancy evaluation of public libraries: Lessons learned from three case studies. Library Leadership \& Management. 2005; 19(1):16-25.

[39] Preiser, W. and Vischer, J. (2005) Assessing Building Performance, Elsevier, Butterworth-Heinemann.

[40] Preiser, W.F.E. (1998). Health Center Post-Occupancy Evaluation: Toward Community-Wide Quality Standards. Proceedings of the NUTAU/USP Conference, Sao Paulo, Brazil.

[41] Natasha, K. (2008). "Performance Analysis of Government and Public Building via Post Occupancy Evaluation." Asian Social Science, Vol, 4. No.9. September 2008

[42] Wauters, B. (2005), "The added value of facilities management: benchmarking work processes", Facilities, Vol. 23 Nos 3/4, pp. 142-51

[43] Friesen, S., L. Trojan, et al. (2008). "Relating Health Care Environment Design to Health Quality Outcomes: Post Occupancy Evaluation of The Ward of the 21st Century (Final Report)."

[44] Hafizi. Z., K. A., S. A., K. A., \& Z. F. (2010). Pengurusan Fasiliti Dalam Penyelenggaraan Bangunan: Amalan Kualiti, Keselamatan dan Kesihatan. Journal of Techno-Social, 23-36.

[45] Hashim AE, Hasnizan A, Hasim MS, Samikon AS (2015), Health Care Building Assessment through Post Occupancy Audit, Asia Pacific International Conference on Environment-Behaviour Studies, AicE-Bs2015, 30 August04 September 2015, Barcelona, Spain, Procedia - Social and Behavioural Sciences.

[46] Izran, Hakim, \& Shardy (2007). Post Occupancy Evaluation: The Answer for the Sustainability of Malaysia's Built Environment. Proceedings of the International Conference on Built Environment in Developing Countries. 3-4 December 2007. Universiti Sains Malaysia.

[47] Nik-Mat, N. E. M., S. N. Kamaruzzaman, et al. (2011). "Assessing the Maintenance Aspect of Facilities Management through a Performance Measurement System: A Malaysian Case Study "The 2nd International Building Control Conference 2011.

[48] Hassanain, M.A. (2008), "On the performance evaluation of sustainable student housing facilities", Journal of Facilities Management, Vol. 6 No. 3, pp. 212-25.

[49] Preiser, W. F. E. (2002). Improving Building Performance. Washington D.C: NCARB.

[50] University of Westminster (2006). Guide to Post Occupancy Evaluation. HEFCE.

[51] Izran, S. M. (2011). Post Occupancy Evaluation of Building Performance in Malaysia. Doctor of Philosophy (Facilities Management), Universiti Teknologi Malaysia. 